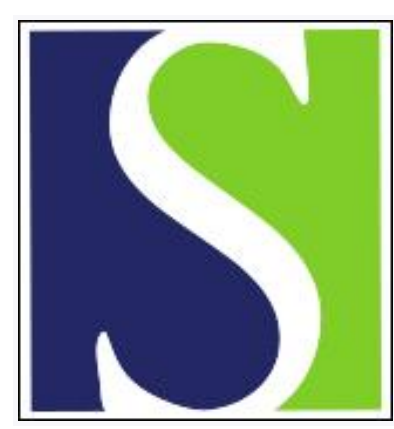

Scand J Work Environ Health 1986;12(6):545-551

https://doi.org/10.5271/sjweh.2102

Issue date: Dec 1986

Mortality and cancer morbidity among workers in a chemical factory.

by Hagmar L, Bellander T, Englander V, Ranstam J, Attewell R, Skerfving $\mathrm{S}$

This article in PubMed: www.ncbi.nlm.nih.gov/pubmed/3823803 


\title{
Mortality and cancer morbidity among workers in a chemical factory
}

\author{
by Lars Hagmar, MD, ${ }^{1}$ Tom Bellander, MEng, ${ }^{1}$ Viveka Englander, ${ }^{1}$ Jonas Ranstam, BSc,,${ }^{1,2}$ \\ Robyn Attewell, MSc, ${ }^{1,2}$ Staffan Skerfving, $\mathrm{MD}^{1}$
}

\begin{abstract}
HAGMAR L, BELLANDER T, ENGLANDER V, RANSTAM J, ATTEWELL R, SKERFVING S. Mortality and cancer morbidity among workers in a chemical factory. Scand J Work Environ Health 12 (1986) 545-551. A retrospective cohort study was performed on a group of 664 male workers employed for at least one month during the period 1942-1979 in a chemical factory. Both established and suspected carcinogens had been handled in the plant, primarily piperazine, but also urethane, ethylene oxide, formaldehyde, and organic solvents. A significantly increased mortality, compared with the regional death rate, was observed in the cohort. The increase was mairily due to violent deaths and cardiovascular diseases. No rise in death rates was observed for asthma, bronchitis or emphysema, in spite of other evidence of a high risk of occupational asthma, due to exposure to piperazine. A statistically significant increase in cancer morbidity was observed for malignant lymphoma/myelomatosis when an induction latency time of at least 10 years was used. Furthermore, an increase in bronchial cancer was noted, but it was statistically significant only when an induction-latency time of at least 15 years was used. A case-referent study within the cohort did not reveal any significant association between any specific chemical exposure and cancer morbidity.
\end{abstract}

Key terms: cohort study, case-referent study, asthma, malignant lymphoma, myelomatosis, bronchial cancer, piperazine, urethane.

Increased cancer mortality has previously been shown among workers from the chemical industry $(5,25)$. In a Swedish chemical plant several different carcinogens have been handled. Thus, it was considered essential to study the mortality and cancer morbidity of a cohort of workers from this factory.

\section{Subjects and methods}

\section{The plant}

Several hundred chemicals, some of which are established or suspected carcinogens, had been handled in the plant since it was founded in the 1940s.

Piperazine, a secondary heterocyclic amine, which is an established inducer of occupational asthma (9, $10,21,27)$, had been one of the main products in the plant since the early 1950s. As many as a third of the workers heavily exposed to this compound may develop asthma (10). Furthermore piperazine nitrosates easily in humans into carcinogenous nitrosopiperazines. This action has been observed both after ingestion of a normal anthelmintic dose and after occupational exposure to piperazine $(3,4)$. Due to technical improvements at the plant, the exposure levels decreased considerably during the late 1970s. Breathing zone sampling was per-

\footnotetext{
1 Department of Occupational Medicine, University Hospital, S-221 85 Lund, Sweden.

2 Regional Tumour Register, University Hospital, S-221 85 Lund, Sweden.
}

Reprints requests to: Dr L Hagmar, Department of Occupational Medicine, University Hospital, S-221 85 Lund, Sweden. formed in 1980. The time-weighted average (TWA) estimated for one work process on four different occasions, a total of $38 \mathrm{~h}$ of sampling time, was 1.2 $\mathrm{mg} / \mathrm{m}^{3}(9)$.

Urethane and formaldehyde, both of which are carcinogenic in rodents $(15,17)$, were handled in the plant, the former from 1958 to 1976 and the latter from the late 1950 s on.

Benzyl chloride, which is mutagenic and possibly carcinogenic in rodents (16), was handled from 1970 to 1976 . In the synthesis of piperonyl butoxide (19691974), there may have been formation of bis(chloromethyl)ether (BCME), which causes cancer in humans (15). However, no adequate air analysis of any of these substances was ever performed in the plant.

Ethylene oxide, even in low concentrations, is genotoxic in humans (14), and in previous epidemiologic studies it has been associated with an increased incidence of cancer, especially leukemia $(12,13)$. This chemical had been handled at the plant since 1958 . Breathing-zone samples (during a total time of $32 \mathrm{~h}$ ) performed since 1976 had a TWA of $1.5 \mathrm{ppm}$.

Epichlorohydrin, an alkylating agent, is mutagenic in different test systems and carcinogenic in rats (17). It is also possibly a lung carcinogen in man $(7,31)$. Epichlorohydrin had been used in the plant since 1974. Breathing-zone sampling performed since 1979 (during a total time of $6 \mathrm{~h}$ and on different occasions) had a TWA of $0.15 \mathrm{ppm}$. There is however reason to believe that the exposure levels from 1974 to 1979 were substantially higher.

Different organic solvents, especially toluene, had been used all over the plant in numerous work opera- 
tions since the plant was founded. Exposure to solvents has been associated with malignant lymphoma $(11,26)$. The use of organic chemicals, mainly pharmaceutical products, surface-active agents, organic chelating agents, and micronutrients for plants, was not extensive until the early 1960 s.

\section{Cohort study}

The cohort included all 664 male workers born in 1895 or later and employed at least one month during the period from 1942 to 30 April 1979 (figure 1). As the company records, containing name, date of birth, native country, address, and start and end of employment, were incomplete for the period before 1965 , information on 120 of the subjects was obtained through interviews with a previous staff manager, and with foremen or workers employed for a long time. Verification of these data was obtained by direct contact with the 98 men who were still alive and with the nearest living relative of the 22 deceased subjects.

There were only 60 immigrant workers, of which 32 were of Danish origin, in the cohort.

Vital status of the whole cohort was determined up to 31 December 1984.

All death certificates were obtained. They had been coded according to the International Classification of Diseases (ICD) by the National Swedish Central Bureau of Statistics, which is responsible for the coding of all Swedish death certificates. All codes were transformed to the eighth revision of the ICD. A total of $60 \%$ of the death certificates was based on forensic or clinical autopsy. Information on tumors (coded ac-

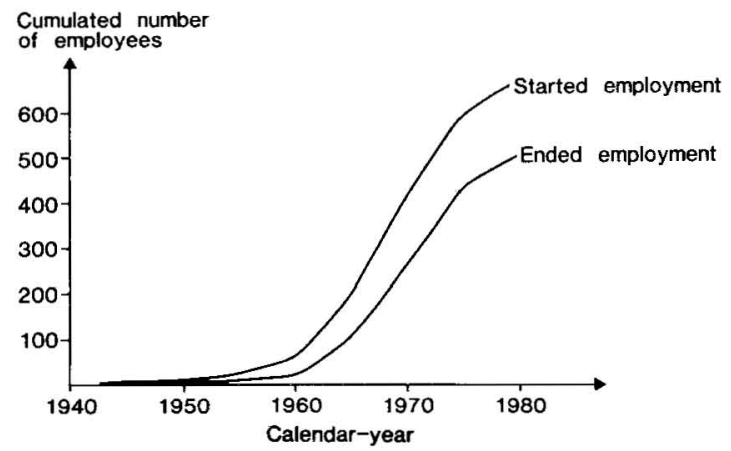

Figure 1. Start and end of employment, with respect to calendar year, for the 664 workers in the cohort.

Table 1. Person-years of observation by age and calendar years

\begin{tabular}{|c|c|c|c|c|c|}
\hline \multirow{2}{*}{$\begin{array}{l}\text { Calendar } \\
\text { years }\end{array}$} & \multicolumn{4}{|c|}{ Age (years) } & \multirow{2}{*}{ Total } \\
\hline & $\leq 19$ & $20-39$ & $40-59$ & $60-79$ & \\
\hline $\begin{array}{r}1958-1960 \\
1961-1970 \\
1971-1980 \\
1981-1984\end{array}$ & $\begin{array}{r}4.2 \\
17.3 \\
12.3 \\
0.0\end{array}$ & $\begin{array}{r}53.9 \\
1041.1 \\
2289.4 \\
684.9\end{array}$ & $\begin{array}{rr} & 68.7 \\
1 & 116.7 \\
2 & 356.5 \\
1 & 082.1\end{array}$ & $\begin{array}{r}12.6 \\
163.1 \\
788.6 \\
512.7\end{array}$ & $\begin{array}{r}139.4 \\
2338.1 \\
5453.8 \\
2279.7\end{array}$ \\
\hline Total & 33.8 & 4069.3 & 4630.9 & 1477.0 & 10211.8 \\
\hline
\end{tabular}

cording to the ICD, seventh revision) diagnosed from 1958 to 1982 was obtained from the national Swedish and the southern Swedish regional tumor registers, and for tumors diagnosed in 1983 from the Southern Swedish Regional Tumour Register only. No tumor was identified solely in the national register. Each individual could have more than one tumor registered. Table 1 shows the distribution of person-years by age group and calendar year.

Expected mortality for the period 1961-1984 was calculated with the use of mortality rates (specific for calendar year, cause and five-year age groups) for males in the county (Malmöhus, excluding Malmö town; about 250000 male inhabitants). These rates were calculated from death and population counts obtained from the National Central Bureau of Statistics. Rates for 1983 and 1984 were not available, and so those for 1982 were repeated for these years. Similarily, yearly morbidity rates for cancer in the period 1958 to 1983 for the county were obtained from the Southern Swedish Regional Tumour Register. Date of death or emigration was used as the individual end point. No subjects had emigrated or died before the observation period began.

Cause-specific standardized mortality (or morbidity) ratio (SMR) values were calculated.

Dose-response relationships were analyzed through the linear modeling of trends in SMR with duration of employment (8). The correlation between age and length of employment affects the comparability of the SMR values from each employment stratum and may result in a negative bias for the SMR values, especially for workers employed for a long time. Thus the SMR for each employment stratum was itself standardized, and hence referred to as the SSMR, with respect to a single employment stratum by a system of weighting the age-specific SMR values according to the expected morbidity in the same age group of the standard stratum (28).

The term "significant" refers to a probability of $\leq 0.05$. All tests were two-tailed, except in the analyses of dose-response relationship.

Several hypotheses were addressed in this study. Increased mortality from nonmalignant respiratory diseases could be suspected, due to the asthma-inducing properties of piperazine. Furthermore, exposure to piperazine, as well as to urethane, formaldehyde, organic solvents, and ethylene oxide, may have increased the cancer morbidity. The two latter exposures were regarded as possible inducers of hematologic malignancies. With a reasonable induction-latency time for cancer taken into consideration, the exposures to epichlorohydrin, benzyl chloride, and BCME were too recent to be of any concern.

\section{Matched case-referent study within the cohort}

For all 29 subjects in the exposed cohort who obtained a cancer diagnosis between 1958 and 1983, and for 
three additional subjects with cancer diagnosed in 1984, two referents without cancer and matched for age (mean difference 4.2 years, referents being younger), first time of employment (mean difference 2.2 years, referents being employed later), and length of employment (mean difference 1.8 years, referents being employed for a shorter time) were selected from the cohort.

In a second analysis, for each case of malignant lymphoma/myelomatosis, bladder cancer, or bronchial cancer, two additional referents were selected according to the same matching criteria from the pool of referents primarily matched with the other cancer cases.

Information on lifetime smoking habits and previous employment was collected by interviews with the subjects, or, if they were deceased, with their nearest living relative. Their employment was assessed regarding possible chemical exposure. Furthermore previous employment was also checked through employee records from a rubber factory, two paint-manufacturing plants, a rotogravure printing office, and another chemical factory (producing inorganic acids) in the same city.

For all but three of the cases and two of the referents, one of the foremen, employed since the 1950s at the chemical plant under study, performed a "blinded" estimation of worktime at various work processes involving possible exposure to the established or suspected carcinogens. As both organic solvents and formaldehyde had been used in numerous different work operations at the plant, it was not feasible to evaluate each worker's individual exposure to these agents.

With the conditional likelihood procedure, the matched sets were analyzed with a score test (6). All stated p-values are two-tailed.

\section{Results}

\section{Mortality}

The overall mortality ratio for the period 1961 to 1984 was statistically significantly increased ( 88 observed deaths versus 68.7 expected, SMR $128, p=0.02$ ) (table 2). As to cause-specific mortality, there was a significantly increased risk of malignant lymphoma and myelomatosis (SMR 327, p = 0.04). No statistically significantly increased risk for death from asthma, bronchitis, or emphysema was observed (SMR 204, $\mathrm{p}=0.18$ ). On the other hand, there was an increased risk of violent death (SMR 190, p $=0.01$ ).

When at least six months of employment and at least 10 years of induction-latency time was used, the overall mortality ratio was still slightly elevated (SMR 130), but, probably due to the diminished number of personyears under observation, it was not statistically significant. The risk for death due to malignant lymphoma and myelomatosis did, however, increase (SMR 479, $p=0.03$ ). Furthermore the risk for death from bronchial cancer was increased, but was still not statistically significant (SMR 228, $\mathrm{p}=0.07$ ).

\section{Cancer morbidity}

During the period 1958 to 1983,32 cancers, in 29 subjects, were registered in the cohort compared with 30.8 expected (SMR 104, p > 0.5) (table 3). The morbidity ratio for malignant lymphoma and myelomatosis was significantly increased (SMR $270, p=0.04)$. An increase in bladder cancer was also observed (SMR 200), but it did not reach statistical significance.

When at least six months of employment and at least 10 years of induction-latency time was used, the overall

Table 2. Observed $(O)$ and expected $(E)$ mortality and causes of death in the cohort in 1961-1984. (Restricted cohort = time of employment of $\geq 6$ months and an induction-latency time of $\geq 10$ years, SMR = standardized mortality ratio)

\begin{tabular}{|c|c|c|c|c|c|c|c|c|}
\hline \multirow{2}{*}{$\begin{array}{l}\text { Cause of } \\
\text { death }^{\mathrm{a}}\end{array}$} & \multicolumn{4}{|c|}{ Total cohort ${ }^{b}$} & \multicolumn{4}{|c|}{ Restricted cohortc } \\
\hline & 0 & $E$ & SMR & $\mathrm{p}$ & 0 & $E$ & SMR & $p$ \\
\hline $\begin{array}{l}\text { Malignant tumors } \\
(140-209)\end{array}$ & 21 & 17.8 & 118 & 0.45 & 14 & 10.1 & 138 & 0.22 \\
\hline $\begin{array}{l}\text { Bronchial cancer (162) } \\
\text { Lymphomas and mye- } \\
\text { lomatosis }(200-203)\end{array}$ & $\begin{array}{l}6^{d} \\
4\end{array}$ & $\begin{array}{l}3.6 \\
1.2\end{array}$ & $\begin{array}{l}166 \\
327\end{array}$ & $\begin{array}{l}0.19 \\
0.04\end{array}$ & $\begin{array}{l}5 \\
3\end{array}$ & $\begin{array}{l}2.2 \\
0.6\end{array}$ & $\begin{array}{l}228 \\
479\end{array}$ & $\begin{array}{l}0.07 \\
0.03\end{array}$ \\
\hline $\begin{array}{l}\text { Circulatory organs } \\
(390-458)\end{array}$ & 37 & 30.7 & 120 & 0.25 & 25 & 18.7 & 134 & 0.14 \\
\hline $\begin{array}{l}\text { Nonmalignant respiratory } \\
\text { diseases }(460-519)\end{array}$ & 3 & 3.0 & 100 & $>0.5$ & 1 & 1.8 & 56 & $>0.5$ \\
\hline $\begin{array}{l}\text { Asthma, bronchitis, and } \\
\text { emphysema (490-493) }\end{array}$ & 3 & 1.5 & 204 & 0.18 & 1 & 0.9 & 110 & $>0.5$ \\
\hline $\begin{array}{l}\text { Violent deaths and } \\
\text { intoxications }(800-999)\end{array}$ & 19 & 10.0 & 190 & 0.01 & 8 & 3.5 & 231 & 0.03 \\
\hline Other causes & 8 & 7.2 & 111 & $>0.5$ & 1 & 3.0 & 34 & $>0.5$ \\
\hline All causes $(0-999)$ & 88 & 68.7 & 128 & 0.02 & 49 & 37.6 & 130 & 0.06 \\
\hline
\end{tabular}

a Code of the International Classification of Diseases, eighth revision, in parentheses.

10074 person-years.

c 3304 person-years.

d One of these cases was a stomach cancer, but it had been misclassified in the Registry of Causes of Death as a bronchial cancer. 
Table 3. Observed $(O)$ and expected $(E)$ cancer morbidity of the cohort in 1958-1983. (Restricted cohort = time of employment of $\geq 6$ months and induction-latency time of $\geq 10$ years, SMR = standardized morbidity ratio)

\begin{tabular}{|c|c|c|c|c|c|c|c|c|}
\hline \multirow{2}{*}{$\begin{array}{l}\text { Type of } \\
\text { cancer }\end{array}$} & \multicolumn{4}{|c|}{ Total cohort ${ }^{b}$} & \multicolumn{4}{|c|}{ Restricted cohort ${ }^{c}$} \\
\hline & 0 & $\mathrm{E}$ & SMR & $p$ & 0 & $\mathbf{E}$ & SMR & $p$ \\
\hline $\begin{array}{l}\text { Bronchial cancer (162.1) } \\
\text { Urinary bladder cancer (181.0) } \\
\text { Lymphomas and myelo- } \\
\text { matosis }(200-203)\end{array}$ & $\begin{array}{l}5 \\
5 \\
5\end{array}$ & $\begin{array}{l}3.6 \\
2.5 \\
1.9\end{array}$ & $\begin{array}{l}140 \\
200 \\
270\end{array}$ & $\begin{array}{l}0.42 \\
0.11 \\
0.04\end{array}$ & $\begin{array}{l}5 \\
2 \\
4\end{array}$ & $\begin{array}{l}2.0 \\
1.4 \\
0.9\end{array}$ & $\begin{array}{l}247 \\
141 \\
462\end{array}$ & $\begin{array}{r}0.06 \\
>0.5 \\
0.01\end{array}$ \\
\hline Other cancers & 17 & 22.9 & 74 & $>0.5$ & 11 & 12.2 & 90 & $>0.5$ \\
\hline All cancers $(140-209)$ & 32 & 30.8 & 104 & $>0.5$ & 22 & 16.5 & 133 & 0.17 \\
\hline
\end{tabular}

a Code of the International Classification of Diseases, seventh revision, in parentheses.

b 9653 person-years.

c 2968 person-years.

Table 4. Observed (O) cancer morbidity and age-standardized morbidity ratio (SMR, SSMR), 1958-1983, compared to those of the county for different durations of employment, with an induction-latency time of $\geq 10$ years. (SMR $=$ standardized morbidity ratio, SSMR = SMR standardized with respect to the age distribution of the first (shortest) employment stratum)

\begin{tabular}{|c|c|c|c|c|c|c|c|}
\hline \multirow{3}{*}{ Site } & \multicolumn{6}{|c|}{ Duration of employment (years) } & \multirow{3}{*}{$\begin{array}{l}\text { Trend } p \text {-value } \\
\text { (one-tailed) }\end{array}$} \\
\hline & \multicolumn{2}{|c|}{$<1$} & \multicolumn{2}{|c|}{$1-3$} & \multicolumn{2}{|c|}{$\geq 4$} & \\
\hline & 0 & SMR & 0 & SSMR & 0 & SSMR & \\
\hline All $(140-209)$ & 2 & 48 & 6 & 102 & 15 & 167 & $<0.0001$ \\
\hline
\end{tabular}

a Code of the International Classification of Diseases, seventh revision, in parentheses.

morbidity ratio increased slightly (SMR 133), but not significantly. However, the morbidity ratio for malignant lymphoma and myelomatosis increased further (SMR 462, $\mathrm{p}=0.01$ ). The increase in bronchial cancer was almost statistically significant (SMR $247, \mathrm{p}=$ $0.06)$. This increase seemed to be related to the induction-latency period, as a further increase of risk was observed when 15 years of induction-latency time was used (SMR 337, $\mathrm{p}=0.03$ ).

There was a statistically significant linear doseresponse relationship between duration of employment and morbidity for all cancer $(\mathrm{p}<0.0001)$ (table 4$)$.

\section{Matched case-referent study in the cohort}

Table 5 summarizes the characteristics of the cases and referents. There was no overrepresentation of smokers among the cases or of previous possible chemical exposure. Thirty-eight percent of the cases had been exposed to piperazine on more than singular occasions, compared with $31 \%$ of the referents $(p=0.38)$. Thirty-one percent of the cases had been exposed to urethane in the same manner, compared with $16 \%$ of the referents $(p=0.14)$. Only $3 \%$ of the cases had been exposed to ethylene oxide and none to benzyl chloride, BCME, or epichlorohydrin.

The cases of malignant lymphoma/myelomatosis, bronchial cancer, and bladder cancer did not differ from their referents with respect to smoking habits and previous possible chemical exposure (table 5). It is, however, noteworthy that one of the subjects with bladder cancer had, during the period 1943 to 1965 , been mixing rubber in a rubber factory, and another had worked for five months in 1957 as a storeman in the same plant.

There were numerical, but not statistically significant, increases in the incidence of exposure of the cases as compared to referents in regard to urethane/ bronchial cancer ( 40 versus $10 \%, \mathrm{p}=0.11$ ), urethane/ lymphoma ( 50 versus $20 \%, \mathrm{p}=0.15$ ), and piperazine/ lymphoma (50 versus $26 \%, \mathrm{p}=0.41$ ).

\section{Discussion}

$\wedge$

\section{Validity}

No preemployment health examination was performed before 1972, when the company founded its medical health service. In addition the occurrence of occupational asthma at the plant had not been given any particular attention by the medical health service until 1979. It is therefore unlikely that any bias in the selection of employees into the cohort affected mortality from nonmalignant respiratory diseases.

A more vital problem is that information on $18 \%$ of the subjects in the cohort was not obtained from the company record, but through other means. Ten of these 120 subjects later developed cancer. Howev$\mathrm{er}$, none of these cases was diagnosed during employment. Thus there is no reason to believe that subjects with cancer were more likely to be recalled by the persons interviewed.

An underascertainment of short-term employees may have affected the mortality patterns, as such a group might have a higher than average mortality. However, 
Table 5. Exposure of the 32 subjects with cancer ("cases") and their 64 referents to possible risk factors for cancer. ( $N=$ number of subjects for which information was available)

\begin{tabular}{|c|c|c|c|c|c|c|c|c|c|c|c|c|c|c|c|c|}
\hline \multirow{3}{*}{ Risk factor } & \multicolumn{4}{|c|}{ All cancers } & \multicolumn{4}{|c|}{ Lymphomas $^{a}$} & \multicolumn{4}{|c|}{ Bronchial cancers } & \multicolumn{4}{|c|}{ Bladder cancers } \\
\hline & \multicolumn{2}{|c|}{ Cases } & \multicolumn{2}{|c|}{ Referents } & \multicolumn{2}{|c|}{ Cases } & \multicolumn{2}{|c|}{ Referents } & \multicolumn{2}{|c|}{ Cases } & \multicolumn{2}{|c|}{ Referents } & \multicolumn{2}{|c|}{ Cases } & \multicolumn{2}{|c|}{ Referents } \\
\hline & $N$ & $\%$ & $\mathrm{~N}$ & $\%$ & $\mathrm{~N}$ & $\%$ & $\mathrm{~N}$ & $\%$ & $N$ & $\%$ & $\mathrm{~N}$ & $\%$ & $\mathrm{~N}$ & $\%$ & $N$ & $\%$ \\
\hline Smoking & 32 & 77 & 62 & 88 & 5 & 80 & 20 & 90 & 5 & 100 & 20 & 90 & 5 & 100 & 20 & 80 \\
\hline \multicolumn{17}{|l|}{$\begin{array}{l}\text { Previous chemical } \\
\text { exposure }\end{array}$} \\
\hline $\begin{array}{l}\text { History } \\
\text { Records }\end{array}$ & $\begin{array}{l}32 \\
32\end{array}$ & $\begin{array}{l}41 \\
34\end{array}$ & $\begin{array}{l}64 \\
64\end{array}$ & $\begin{array}{l}38 \\
45\end{array}$ & $\begin{array}{l}5 \\
5\end{array}$ & $\begin{array}{l}40 \\
60\end{array}$ & $\begin{array}{l}20 \\
20\end{array}$ & $\begin{array}{l}45 \\
75\end{array}$ & $\begin{array}{l}5 \\
5\end{array}$ & $\begin{array}{l}40 \\
20\end{array}$ & $\begin{array}{l}20 \\
20\end{array}$ & $\begin{array}{l}30 \\
35\end{array}$ & $\begin{array}{l}5 \\
5\end{array}$ & $\begin{array}{l}20 \\
40\end{array}$ & $\begin{array}{l}20 \\
20\end{array}$ & $\begin{array}{l}35 \\
35\end{array}$ \\
\hline \multicolumn{17}{|l|}{$\begin{array}{l}\text { Exposure in } \\
\text { present plant }\end{array}$} \\
\hline $\begin{array}{l}\text { Piperazine } \\
\text { Urethane } \\
\text { Benzyl chloride } \\
\text { Bis(chloromethyl)ether } \\
\text { Ethylene oxide } \\
\text { Epichlorohydrin }\end{array}$ & $\begin{array}{l}29 \\
29 \\
32 \\
32 \\
29 \\
32\end{array}$ & $\begin{array}{r}38 \\
31 \\
0 \\
0 \\
3 \\
0\end{array}$ & $\begin{array}{l}62 \\
62 \\
64 \\
64 \\
62 \\
64\end{array}$ & $\begin{array}{r}31 \\
16 \\
2 \\
5 \\
8 \\
3\end{array}$ & $\begin{array}{l}4 \\
4 \\
5 \\
5 \\
4 \\
5\end{array}$ & $\begin{array}{r}50 \\
50 \\
0 \\
0 \\
25 \\
0\end{array}$ & $\begin{array}{l}19 \\
20 \\
20 \\
20 \\
19 \\
20\end{array}$ & $\begin{array}{r}26 \\
20 \\
0 \\
5 \\
21 \\
0\end{array}$ & $\begin{array}{l}5 \\
5 \\
5 \\
5 \\
5 \\
5\end{array}$ & $\begin{array}{r}40 \\
40 \\
0 \\
0 \\
0 \\
0\end{array}$ & $\begin{array}{l}20 \\
20 \\
20 \\
20 \\
20 \\
20\end{array}$ & $\begin{array}{r}30 \\
10 \\
0 \\
0 \\
5 \\
0\end{array}$ & $\begin{array}{l}4 \\
4 \\
5 \\
5 \\
4 \\
5\end{array}$ & $\begin{array}{r}25 \\
25 \\
0 \\
0 \\
0 \\
0\end{array}$ & $\begin{array}{l}19 \\
19 \\
20 \\
20 \\
19 \\
20\end{array}$ & $\begin{array}{r}37 \\
16 \\
0 \\
0 \\
16 \\
5\end{array}$ \\
\hline
\end{tabular}

a Including myelomatosis.

cross-sectional estimates of the number of employees in the plant in different years, as derived from the cohort (figure 1), fits very well with independent data from the company. Thus such an underascertainment, which would bias our results in a "conservative" way, must be very limited.

Diagnostic accuracy for tumors, as well as for causes of death, is important for the validity of the study. Information on cause of death was obtained for all the deceased workers in the cohort, and $60 \%$ of the death certificates were based on clinical or forensic autopsy, which is in accordance with the frequency of autopsies of deceased males in the county during the period 1969 to $1978(30)$.

Errors in both the Register of Causes of Death and the tumor registers have been detected through quality studies $(19,30)$. A few such errors were present in this cohort. One case of colon cancer, according to the death certificate, was missing in the tumor registers, and one case of stomach cancer was falsely registered as bronchial cancer in the Register of Causes of Death.

Only three of the 29 subjects with cancer diagnosed during the period 1958 to 1983 were submitted to the hospital by the company's medical health service, and none of the cases were detected through any health screening program. Thus there is no basis for suspecting that the increased incidences of tumors were due to a more intense medical surveillance of the employees in the cohort than of the regional population.

The cohort has been geographically stable, as until July 1986 only 86 subjects had moved from Malmöhus County to other parts of Sweden. Thus, as there are substantial regional differences in incidence rates for causes of death (30), as well as for cancer morbidity (23), it was reasonable to employ county rates instead of national ones.

Smoking is a possible confounding factor for bronchial cancer. Smoking habits were, through a questionnaire on occupational asthma (10), known for 507 of the 644 subjects in the cohort. Fifteen percent were lifelong nonsmokers, $55 \%$ had a life consumption of
1-20 pack-years (pack-year $=$ cigarettes per day multiplied by years of smoking, divided by 20 ), and the remaining $30 \%$ had a life consumption of more than 20 pack-years. This proportion of smokers is similar to that of Swedish industrial workers in general (24), but higher than among the adult population in Malmöhus County (29). This finding may explain some of the increased morbidity from bronchial cancer.

On the assumption of a mean smoking period of 30 years, the risk of bronchial cancer, compared with that of nonsmokers, is about five times higher for "moderate" smokers and about 15 times higher for "heavy" smokers (20). On the basis of these figures, the abundant smoking in the cohort, compared with that of the general population, could explain an SMR of about 185 (2).

\section{Mortality}

An interesting observation was that, in spite of the increased overall mortality ratio of the cohort, no rise in deaths from asthma, bronchitis, or emphysema was found. Thus, even if as many as $30 \%$ of the workers most heavily exposed to piperazine in the plant experienced bronchial asthma (10), it did not affect the mortality ratio. However, it is of course possible that the occurrence of occupational asthma in some subjects may have contributed to death from cardiovascular diseases. The follow-up period is also still short.

In most cohort studies of industrial workers no increased overall mortality ratio is found, and this state has usually been ascribed to the "healthy worker effect" (22). Thus the increased overall mortality in this cohort is somewhat remarkable. The increase was not mainly due to cancer, but rather to violent deaths (no occupational accidents) and cardiovascular diseases. Thus the observed overrisk was probably due to the polluted and worn-out plant, which may have caused a socioeconomic selection impact on the workforce. 


\section{Cancer morbidity}

The most essential result of this study was the significant increase of malignant lymphoma/myelomatosis in the cohort. It is important that all three cases of malignant lymphoma were of non-Hodgkin's type, ie, B-lymphocyte tumors, and thus related to the two cases of myelomatosis. It is thus justified to treat them as one entity. The finding is strengthened by the fact that chemists (18) and other subjects exposed to chemicals, including organic solvents (11), have earlier been claimed to have an overrisk from this kind of tumor. Moreover, during the preparation of this manuscript, a fourth case of non-Hodgkin's lymphoma was diagnosed in the cohort. This subject had been employed in the present plant during the preceding 15 years, and had been substantially exposed to piperazine but not to urethane.

The present case-referent study did not give any evidence as to etiologic agents of the malignant lymphoma and myelomatosis. However, partly due to the few cases of cancer and partly due to the complexity of the exposure, this method is insensitive. Some of the workers had solely been exposed to one chemical during their employment. However, others had been exposed to several, eg, $29 \%$ of those exposed to piperazine had also been exposed to urethane. Furthermore the influence of the exposure to organic solvents, previously associated with lymphoma (11), could not be evaluated.

Part of the increased risk for bronchial cancer may be explained by the abundant smoking habits in the cohort. On the other hand, the positive relationship between length of induction-latency time and morbidity ratio may favor an association with the work environment. In any case, an increased incidence of bronchial cancer was not due to BCME or epichlorohydrin, as none of the cases had ever been exposed. There was a prevalent exposure to formaldehyde in the plant. A possible risk of bronchial cancer has earlier been noted for workers exposed to that agent (1). The same is true as regards the present study.

The plant involves a complicated pattern of varying exposure to many chemicals over time. It is thus not possible to know whether the observed tumor clusters are solely due to historical exposure or whether one or several carcinogens are still operating. In order to determine if carcinogenic exposure is still present, a study on cytogenetic effects and the excretion of mutagens in the urine has been initiated in the plant. The results of that study may enlighten us with regard to this question.

\section{Acknowledgments}

The project was supported by generous grants from the Swedish Work Environment Fund (ASF 80-218) and from Ellen, Walter, and Lennart Hesselman's Foundation for Scientific Research.
Valuable assistance has been provided by $\mathrm{MrO}$ Brandt, Mr F Bröndum, Mr S Carlsson, Mr S Högman, Ms E Kriple, Ms K Larsson, Mr T Möller, Mr T Nilsson, Mr A Olsson, Mr K Olsson, Ms C Paradis, Ms E Pålsson and Ms K Sjöland.

\section{References}

1. Acheson ED, Barnes HR, Gardner MJ, Osmond C, Pannet B, Taylor CP. Formaldehyde in the British chemical industry: An occupational cohort study. Lancet 1 (1984) 611-616.

2. Axelson O. Aspects on confounding in occupational health epidemiology. Scand J Work Environ Health 4 (1978) $98-102$.

3. Bellander T, Hagmar L, Österdahl BG. Endogen bildning av nitrosamin hos arbetare $\mathrm{i}$ en kemisk industri [Endogenous formation of $N$-mononitrosopiperazine in workers in a chemical industry]. Hygiea 94 (1985) 125.

4. Bellander T, Österdahl BG, Hagmar L. Formation of $\mathrm{N}$-mononitrosopiperazine in the stomach and its excretion in the urine after oral intake of piperazine. Toxicol Appl Pharmacol 80 (1985) 193-198.

5. Bond GG, Reeve GR, Ott MG, Waxweiler RJ. Mortality among a sample of chemical company employees. Am J Ind Med 7 (1985) 109-121.

6. Breslow NE, Day NE. Statistical methods in cancer research. Volume 1 (The analysis of case-control studies). International Agency for Research on Cancer, Lyon 1980. (IARC scientific publication no 32).

7. Enterline PE. Importance of sequential exposure in the production of epichlorohydrin and isopropanol. Ann NY Acad Sci 381 (1982) 344-349.

8. Gardner MJ, Winter PD. Extensions to a technique for relating mortality and environment - Exemplified by nasal cancer and industry. Scand J Work Environ Health 10 (1984) 219-223.

9. Hagmar L, Bellander T, Bergöö B, Simonsson BG. Piperazine-induced occupational asthma. J Occup Med 24 (1982) 193-197.

10. Hagmar L, Bellander T, Ranstam J, Skerfving S. Piperazine-induced airway symptoms: Exposure-response relationships and selection in an occupational setting. Am J Ind Med 6 (1984) 347-357.

11. Hardell L, Eriksson M, Lenner P, Lundgren E. Malignant lymphoma and exposure to chemicals, especially organic solvents, chlorophenols and phenoxy acids: A case-control study. Br J Cancer 43 (1981) 169-176.

12. Högstedt B, Gullberg B, Hedner K, Kolnig AM, Mitelman F, Skerfving S, Widegren B. Chromosome aberrations and micronuclei in bone marrow cells and peripheral blood lymphocytes in humans exposed to ethylene oxide. Hereditas 98 (1983) 105-113.

13. Hogstedt C, Malmqvist N, Wadman B. Leukemia in workers exposed to ethylene oxide. J Am Med Assoc 241 (1979) 1132-1133.

14. Hogstedt C, Rohlén O, Berndtsson BS, Axelson O, Ehrenberg L. A cohort study of mortality and cancer incidence in ethylene oxide production workers. $\mathrm{Br} \mathrm{J}$ Ind Med 36 (1979) 276-280.

15. International Agency for Research on Cancer. Chemical and industrial processes associated with cancer in humans. Lyon 1979. (IARC monographs on the evaluation of the carcinogenic risk of chemicals to humans, suppl 1).

16. International Agency for Research on Cancer. Some industrial chemicals and dyestuffs. Lyon 1982. (IARC monographs on the evaluation of the carcinogenic risk of chemicals to humans, volume 29).

17. International Agency for Research on Cancer. Chemicals, industrial processes and industries associated with cancer in humans. Lyon 1982. (IARC monographs on 
the evaluation of the carcinogenic risk of chemicals to humans, suppl 4).

18. Li FP, Fraumeni JF, Mantel N, Miller RW. Cancer mortality among chemists. J Natl Cancer Inst 43 (1969) 1159-1164.

19. Mattson B. Cancer registration in Sweden: Studies on completeness and validity of incidence and mortality registers. University of Stockholm, Stockholm 1984. (Doctoral dissertation).

20. MacMahon B, Pugh TF. Epidemiology - Principles and methods. Little, Brown and Company, Boston, MA 1970.

21. McCullagh SF. Allergenicity of piperazine: A study in environmental aetiology. Br J Ind Med 25 (1968) 319325.

22. McMichael AJ. Standardized mortality ratios and the "healthy worker effect": Scratching beneath the surface. J Occup Med 18 (1976) 165-168.

23. Möller T, Jogréus C, Gullberg B, Ranstam J, Westrup C. Cancer incidence in southern Sweden 1978-1982. Onkologiskt Centrum, Lund 1984.

24. National Central Bureau of Statistics. Smoking in Sweden. Stockholm 1965.

25. Norman JE, Robinette CD, Fraumeni JF. The mortality experience of army world war II chemical processing companies. J Occup Med 23 (1981) 818-822.

26. Olsson H, Brandt L. Occupational exposure to organic solvents and Hodgkin's disease in men: A case-referent study. Scand J Work Environ Health 6 (1980) 302-305.
27. Pepys J, Pickering CAC, Loudon HWG. Asthma due to inhaled chemical agents - Piperazine dihydrochloride. Clin Allergy 2 (1972) 189-196.

28. Ranstam J. Comparisons of standardized mortality ratios. Scand J Work Environ Health 10 (1984) 63. (Letter to the editor).

29. Sjukvårdens planerings och rationaliseringsinstitut. Hur mår Du Sverige? Ohälsa och vårdutnyttjande i Sverige - undersökningar om levnadsförhållanden (ULF) som underlag för planering [IIl health and medical care in Sweden - A survey concerning living conditions (ULF) as a basis for planning]. Stockholm 1982: (SPRI-rapport 82). (English summary).

30. Sjukvårdens och socialvårdens planerings och rationaliseringsinstitut. Dödsorsak? Dödsorsaksstatistik som underlag för planering [Cause of death?: Cause-of-death statistics as a basis for planning]. Stockholm 1983. (SPRI-rapport 122). (English summary).

31. Tassignon JP, Bos GD, Craigen AA, Jacquet B, Kueng $\mathrm{HL}$, Lanouziere-Simon C, Pierre C. Mortality in an European cohort occupationally exposed to epichlorohydrin. Int Arch Occup Environ Health 8 (1982) 153158.

Received for publication: 21 March 1986 